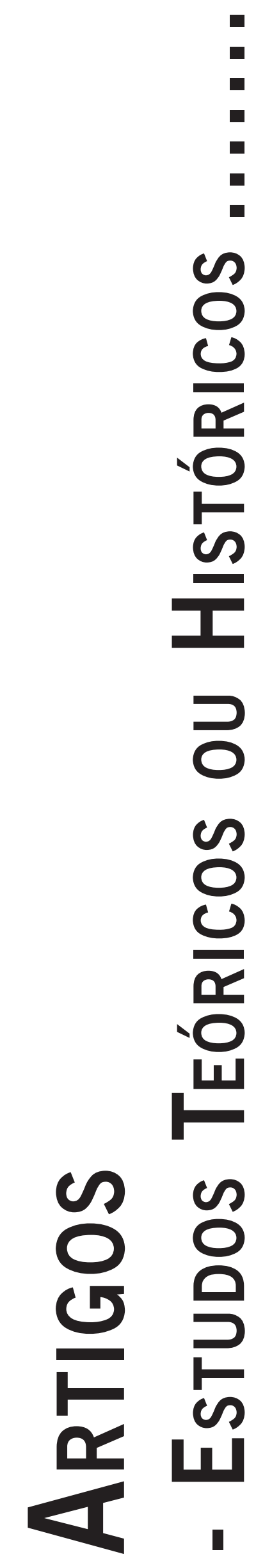




\title{
PESSOAS QUE DEPENDEM DE DROGAS: ENSAIO DE FIGURAS E FECHAMENTOS
}

\author{
People who are Addicted on Drugs: Essay of Figures and Completions \\ Personas que Dependen de las Drogas: Ensayo de Figuras y Completamientos
}

Luiz Gustavo Santos Tessaro

Cleber Gibbon Ratto

\begin{abstract}
Resumo: A dependência química é um assunto muito em voga na atualidade e convoca os profissionais de saúde a pensarem e produzirem conhecimento sobre o tema, a fim de promover um melhor cuidado às pessoas que buscam algum tipo de ajuda. Este trabalho busca contribuir com considerações sobre esse assunto, sob o enfoque teórico da Gestalt-terapia e de sua base filosófica existencial-fenomenológica. Foram construídas algumas vinhetas a partir de situações vivenciadas pelo autor que dispararam reflexões as quais apontaram para a necessidade de um olhar não só sobre o sujeito, mas também sobre as forças que o atravessam e produzem o modo de ser contemporâneo. Também foi possível verificar algumas aproximações entre a visão gestáltica e o campo da Saúde Coletiva.
\end{abstract}

Palavras-chave: Dependência química; Gestalt-terapia; Existencialismo; Fenomenologia; Saúde coletiva.

\begin{abstract}
The addiction is a subject very in vogue nowadays and convenes the health professionals to think and produce knowledge about this topic, in order to promote a better attention to people who search some kind of assistance. This work seeks to contribute with discussions about this issue, under the theoretical approach of Gestalt-therapy and its existential phenomenological philosophical basis. Some vignettes were made from situations experienced by the author, which triggered reflections that appointed to the necessity of a look not only on the subject, but over the strengths that cross and produce the contemporary way of being as well. It was also possible to observe some approaches between the gestalt point of view and the Collective Health field.

Keywords: Addiction; Gestalt-therapy; Existentialism; Phenomenology; Collective health.

Resumen: La dependencia química es un tema muy en boga hoy en día y a los profesionales de salud convoca a pensar y producir conocimiento sobre el tema, con el fin de promover una mejor atención a las personas que buscan algún tipo de ayuda. Este trabajo busca contribuir a las consideraciones sobre este tema, en el marco del enfoque teórico de la terapia Gestalt y su base filosófica existencial-fenomenológica. Se construyeron algunas viñetas de situaciones vividas por el autor que disparó reflexiones que mostraron la necesidad de una mirada no sólo sobre el tema, sino también acerca de las fuerzas que se cruzan y producen la manera contemporánea de ser. Se observó también algunas similitudes entre la visión de la Gestalt y la Salud Colectiva. Palabras clave: Addicción; Terapia gestalt; Existencialismo; Fenomenología; Salud colectiva.
\end{abstract}

\section{Introdução - composição do campo}

Convencionou-se nomear um conjunto de "sinais e sintomas" que acompanham uma determinada forma de uso de substâncias psicoativas de "dependência química". Nomeando, tentou-se dar significado e produzir conhecimento sobre esse fenômeno da experiência existencial singular humana para controlá-lo. É preciso lembrar, no entanto, que a linguagem é nossa "técnica" de domínio do mundo, porém não esgota nunca um fenômeno, permitindo sempre novas aproximações. As toxicomanias são, de fato, provas do quão longe estamos de descrever e controlar a totalidade de um fenômeno.

Este artigo, pois, pretendeu deter-se nesse tema tão cotidianamente presente e carregado de discursos e verdades, por se tratar de uma problemática atual, mas ao mesmo tempo tão distante do óbvio. A Psiquiatria, as psicoterapias de orientação cognitivo-comportamental e as biociências em geral têm monopolizado os estudos sobre as adições, produzindo conhecimento - verdades - e, de forma profícua, contribuído para ampliação do entendimento biológico e comportamental da dependência química, enquanto outras abordagens teóricas dentro do campo da psicologia têm se distanciado da discussão, como é o caso da Gestalt-terapia. Nesse sentido, este trabalho pretendeu contribuir às discussões, trazendo à tona as contribuições da Gestalt-terapia e de suas bases filosóficas para a compreensão do fenômeno da dependência química na contemporaneidade, por meio do levantamento de referências teóricas da Gestalt-terapia úteis à discussão do problema, da relação das referências do campo da Gestalt-terapia com as bases filosóficas de onde elas emergem, da composição de figuras expressivas do fenômeno estudado, situadas na paisagem social 
da qual se destacam, e do ensaio de fechamentos acerca do fenômeno em questão.

Trata-se de um artigo teórico de caráter exploratório do tema, amparado em revisão bibliográfica de produções do campo da Gestalt-terapia, do Existencialismo e da Fenomenologia. Para tanto, pretendeu-se fazer um levantamento de obras produzidas - tais como livros, artigos disponíveis em revistas científicas e bases de dados, entre outras - que contribuíssem para a discussão da problemática proposta. O critério escolhido para a seleção do referido material foi a relevância do conteúdo para as discussões, a credibilidade das fontes e sua fidedignidade ao corpo teórico fundante da Gestalt-terapia. Foram feitas aproximações com as produções levantadas, com as experiências da prática profissional e com reflexões pessoais e analisadores da contemporaneidade, compondo uma produção de caráter ensaístico. Larrosa afirma que o gênero ensaio é

a forma não regulada da escrita e do pensamento, sua forma mais variada, mais proteica, mais subjetiva. Poder-se-ia dizer, talvez, que o ensaio é uma atitude existencial, um modo de lidar com a realidade, uma maneira de habitar o mundo, mais do que um gênero da escrita (Larrosa, 2004, p. 32).

Os transtornos relacionados ao uso de substâncias, a que este estudo se reporta, têm sido largamente estudados e relatados na literatura psicológica e psiquiátrica em virtude de terem grande incidência sobre a população mundial e configurarem-se como problema grave, não somente de saúde, mas de segurança pública e de educação. Os levantamentos epidemiológicos mais recentes realizados pela Organização Mundial da Saúde estimam que entre 3,4\% e 6,6\% da população mundial é composta por pessoas que usam alguma droga ilícita. Destas, de $10 \%$ a 13\% tem problemas relacionados à dependência ou abuso. As substâncias psicoativas, segundo o mesmo estudo, são responsáveis por uma em cada cem mortes de adultos no planeta (World Health Organization [WHO], 2012, p. 1).

As estatísticas mundiais podem, no entanto, minimizar a seriedade do problema e não corresponder perfeitamente (por serem generalizadas) às realidades, sobretudo, dos países emergentes. No caso do Brasil, o II Levantamento Domiciliar Sobre o Uso de Drogas Psicotrópicas avaliou que $12,3 \%$ da população brasileira é composta por indivíduos que são dependentes de Álcool, 10,1\% de Tabaco, 1,2\% de Maconha, 0,5\% de Benzodiazepínicos, 0,2\% de Solventes e Inalantes e 0,2\% de Estimulantes (Carlini, Galduróz, Noto, Fonseca, Carlini, Oliveira, Nappo, Moura, \& Sanchez, 2005, p. 33). Recente pesquisa fomentada pela Secretaria Nacional de Políticas sobre Drogas (SENAD) e desenvolvida pela Fundação Oswaldo Cruz, mostrou que o país tem cerca de 370 mil usuários de Crack e derivados nas suas ca- pitais e Distrito Federal (Fiocruz, 2013, p. 4). Se tomarmos como objeto de estudo a população de crianças e adolescentes em situação de rua e que não moram com a família: 49,5\% faz uso diário de alguma substância psicoativa no país (Noto, Galduróz, Nappo, Fonseca \& Carlini, 2003, p. 31).

Pesquisas também apontam variações significativas na Região Sul em comparação ao restante do Brasil. A droga com maior número de dependentes nessa delimitação geográfica é o Tabaco, com 10,7\% dos usuários, seguida do Álcool, com 9\%, da Maconha, com 1,1\%, dos Estimulantes, com 0,3\% e dos Benzodiazepínicos, com 0,2\% (Carlini et al., 2005, p. 263). Dados apontam ainda que $82,5 \%$ da população de infantes e adolescentes com laços familiares rompidos e em situação de rua utilizam drogas psicotrópicas diariamente nessa região. No período pesquisado, cerca de $95,6 \%$ dessa amostra populacional havia usado no último mês (Noto, Galduróz, Nappo, Fonseca \& Carlini, 2003, p. 206).

O problema - se é que algum dia ficou restrito às camadas populares da sociedade - abrange as mais diversas classes e tem exigido do poder público e dos demais órgãos competentes, incessantes tentativas de intervenção, algumas interessantes, outras passíveis de discussão e polêmica. É o caso de políticas adotadas no estado de São Paulo que vêm sendo debatidas sem consenso técnico a respeito. Produzir conhecimento científico sobre a questão das adições é, portanto, de suma importância, não apenas para um melhor entendimento do fato e para melhores intervenções no âmbito da saúde mental, mas também para formulação de políticas públicas efetivas e comprometidas com os princípios éticos que norteiam os direitos humanos e a saúde pública brasileira.

Cabe ainda destacar que minha prática em campos profissionais onde a dependência química era tratada mostrou o quanto é importante trabalhar não apenas o comportamento adicto, mas as questões de ordem existencial que fazem o sintoma se estabelecer como figura e a relação do paciente com a droga, que é ímpar. Esses locais, a título de destaque, foram: um hospital geral com setor especializado no tratamento da toxicomania e, portanto, com leitos de internação para dependência química; um serviço de telessaúde do governo federal, que atende o país inteiro fornecendo acompanhamento telefônico para usuários, familiares e amigos de dependentes químicos, além de orientações e informações sobre drogas para toda a população; e uma organização não governamental que presta atendimento psicológico gratuito ao público de baixa renda da região onde está alocada.

Em geral, as terapêuticas dominantes têm dificuldade de contribuir com um processo de singularização e autonomia, trabalhando mais em uma lógica de controle - que pode ser útil em um primeiro momento - que de resolução. Há muitos casos em que o paciente acaba utilizando de seus recursos de saúde para desenvolver linhas de fuga, para criar outros sentidos para sua existência, 
mesmo que as propostas de cuidado estejam muito mais fixadas na doença.

Outro dado que a experiência profissional trouxe, foi o quanto as demandas sociais no campo da dependência química hoje são produzidas, o quando as famílias e os usuários envolvidos procuram os profissionais de saúde já com um discurso pronto de crença de cura fundamentado em um paradigma hospitalar, cartesiano e biomédico e o quanto isso gera ônus para todo um sistema de saúde, não promove a reforma psiquiátrica e não resolve questões psicológicas individuais e coletivas nevrálgicas, apenas esbate - temporariamente - sintomas. Não foram poucos os familiares que ouvi afirmando ideias como: "CAPS não adianta, o único jeito pra ele é internação" (sic), "ele precisa de remédio" (sic), "fazenda não adianta, não prendem ele lá" (sic), "não quero acompanhamento agora não... preciso resolver esse problema da internação dele primeiro" (sic), entre outras. Tais discursos deixam claro que a esperança está depositada numa lógica anacrônica e apontam para os desafios do psicólogo na quebra de tais construções. Diante do exposto, não sentir uma angústia pela falta de outros filtros teóricos consistentes que possibilitassem o cuidado dessa população tornou-se quase impossível.

Essa discussão sobre os modelos de assistência desenvolvidos no âmbito das políticas públicas sobre drogas é um tema capital atualmente, tendo sido objeto de publicações dos sistemas de conselhos, a destacar, a título de exemplo, o Conselho Regional de Psicologia do Rio Grande do Sul (CRPRS), o Conselho Federal de Psicologia (CFP) e o Conselho Regional de Psicologia de São Paulo (CRPSP). Em uma dessas publicações, o CRPRS problematiza, afirmando que, embora tenha havido avanços na saúde mental, hoje "sujeitos que sofrem do uso abusivo de drogas ainda são, com frequência, submetidos a práticas manicomiais, sendo que os serviços que se responsabilizam por estes cuidados são, muitas vezes, privados" (Passos, 2010).

O Conselho Federal de Psicologia, no exercício de suas funções e na promoção da discussão sobre a questão das práticas disponíveis no campo do cuidado ao usuário de drogas, afirma que há "um descompasso no diálogo das complexas necessidades dos usuários com os modelos de acolhimento e assistência, ressaltando soluções por vezes estigmatizantes, criminalizadoras e preconceituosas, levando a situações de maior sofrimento e abandono" (Goldman, Castro, Silveira, Batisti, Gorgulho, Gonçalves \& Guerra, 2010, p. 11). O Conselho Regional de Psicologia de São Paulo, em publicação sobre o tema, afirma que a "insistência em preconizar o modelo proibicionista e a pedagogia do controle poderá custar a todos nós a perpetuação da inexistência de um autêntico trabalho de prevenção ao uso nocivo de drogas" (CRPSP, 2012, p. 20).

Nesse sentido, a exposição que se segue sobre as contribuições que a Gestalt-terapia tem a oferecer é algo de grande relevância, não somente porque há, relativamente, poucas produções sobre o assunto nessa linha teórica, mas também porque cooperar sob a forma de conhecimento pode (é possível imaginar, não sem ausência de pretensão), somando-se aos demais trabalhos já produzidos, servir como intervenção no campo de saber instituído. Os profissionais que atuam no tratamento da dependência química, se não olharem por outros vieses, correm o risco de reduzir a complexidade do tema, que envolve questões sociais muito amplas.

Este estudo se inicia introduzindo a perspectiva fenomenológico-existencial, que guiou as reflexões sobre o tema. Em seguida, problematiza diversos aspectos da dependência química, tendo como ponto de partida das discussões, pequenas vinhetas, fragmentos de experiências que foram considerados relevantes e que se tornaram figuras em aberto em algum momento.

\section{Os "óculos" fenomenológico-existenciais}

Os “óculos” epistemológicos os quais a Gestalt-terapia e suas bases filosóficas utilizam para ver o mundo, o homem e suas relações, determinam claras diferenças para com as teorias de base positivista. As primeiras, aliás, vieram também como crítica às últimas. Mais do que eleger uma "linha da Psicologia” que fornecesse subsídios teóricos para a compreensão da dependência química, escolher a Gestalt-terapia significou a preferência por uma forma diferente de se pôr em relação, em outras palavras, um jeito característico de ser-no-mundo, de pesquisar e de escrever. Já não é mais uma mera escolha teórica, mas fala de uma forma de ser psicólogo, da tentativa de um estilo próprio.

Optar pela Gestalt-terapia significa, também e logicamente, utilizar outra forma de obter conhecimento que não a do método científico. Tal proposta tem seus ônus, o pior, talvez, a recusa das estabilidades, pois o que é do campo do dialógico, do “entre”, não é mensurável e tampouco conhecido. Não é possível ao certo, durante um percurso como esse, prever aonde se pode chegar ou mesmo se é possível chegar a algum lugar.

É certo que "em toda a forma de psicoterapia se esconde uma visão de homem” (Ribeiro, 2012, p. 43). E não só visão de homem, mas de mundo e de como o homem conhece esse mundo ou esse mundo se dá a conhecer. Ribeiro afirma que "o conceito de mundo da Gestaltterapia emana das suas bases teóricas e seu conceito de pessoa emana de suas filosofias de base” (2011, p. 30). Indelevelmente marcado nessa psicoterapia estão as influências das seguintes teorias de base: a psicologia da Gestalt, a teoria de campo, a teoria holística e a teoria organísmica; ao mesmo tempo, compõe a visão gestáltica três filosofias de base, o humanismo, o existencialismo e a fenomenologia, ancorando uma perspectiva epistemológica alternativa ao método positivista (Ribeiro, 2011, p. 30). 
A Gestalt-terapia vê o mundo como uma grande Gestalt, indivisível e organizada, formada de subtodos regidos por leis intrínsecas ao todo (não provém do caos); o homem está incluído e a compõe (Ribeiro, 2011, p. 52). Nesse sentido não é possível pensar um conceito de mundo e de homem dicotomizando-os, sob o risco de fazer um uso incorreto da própria teoria. O mundo está em constante processo e, estando o homem incluído, este recaptula em si o mundo e os dois se constituem em uma relação de reciprocidade, "pois ambos são da mesma natureza, frutos de mesma ordem e significado” (p. 53). Ribeiro afirma, citando Kurt Koffka, que "a essência do mundo (...) é existir, é como se, nele, essência e existência se confundissem, formando uma totalidade absoluta, sem nenhuma precedência ontológica” (p. 53).

Como exposto anteriormente, a visão de homem da Gestalt-terapia é influenciada por suas filosofias de base, o existencialismo e a fenomenologia, e está intrinsecamente ligada a uma visão de mundo. O Existencialismo tem seu nascimento atribuído ao pensador dinamarquês Soren Aabye Kierkegaard que propunha uma "crítica ao racionalismo, em especial a sua forma idealista e ao primado da razão" (Aranha, 1993, p. 122) em meados do século XIX. Essa corrente filosófica, no entanto, engloba o pensamento de uma série de diferentes autores, cada pensamento com suas ênfases, suas diferenças e suas idiossincrasias. $\mathrm{O}$ que une os existencialistas é a característica em comum de seu pensamento que concebe a filosofia como uma prática de análise do homem no mundo, ou seja, de sua existência. Esse homem "é visto não como um ser universal, diluído na ideia (...), mas antes como um ser particular, concreto, com vontade e liberdade pessoais, consciente e responsável” (Ribeiro, 2012, p. 48). O foco de observação está na relação desse homem singular com o mundo.

No âmbito deste trabalho fui ao encontro de uma proposta de analisar a relação sujeito-droga. Ribeiro cita Kierkegaard que afirmava que a "subjetividade é a verdade, a subjetividade é a realidade” (Ribeiro, 2012, p. 48), logo, para que o ser humano possa conhecer algo é necessário "fazer um apelo à existência, à subjetividade" (Ribeiro, 2012, p. 49). O existencialismo, assim como o humanismo, tem o homem como centro, aferidor de sentido e agente de sua mudança. Poder fazer opções constitui-se na essência do ser, contudo, "entre ser livre e estar livre se interpõe toda a luta pelo poder pessoal” (Ribeiro, 2012, p. 57). O homem torna-se aquilo que escolhe (dentro da possibilidade que dispõe para tanto), que projeta ser. Riberio afirma que "a execução desse projeto, de algum modo, é antevista pelas pessoas, que parecem caminhar na direção de algo, que não se sabe frequentemente o que é, mas que se sente como sendo “por aí”" (Ribeiro, 2012, p. 56). "Por aí” também é a forma que propus relacionar-me com a produção do conhecimento sobre a dependência química, não desve- lando-a (como se já estivesse pronta), mas plasmandoa por meio de minha relação com o cotidiano e a vida. Esse "cotidiano" e essa "vida" a que me refiro, poderiam se expressar das mais diversas formas, sendo, por isso, imprevisíveis. Reportagens de jornal, músicas, filmes, prática diária profissional - referida anteriormente - observações a céu aberto, enfim, absolutamente qualquer experiência tornava-se matéria prima, compondo cenas expressivas que vieram a ser objeto de reflexão, algumas das quais entraram neste breve ensaio.

A fenomenologia, por sua vez, é "o método e a filosofia que fornecem os conceitos básicos para a reflexão existencialista” (Aranha, 1993, p. 304). Tem como precursor Franz Brentano, no final do século XIX, não obstante, Edmund Husserl foi quem "formulou as principais linhas dessa abordagem" (Aranha, 1993, p. 123). Ela nos traz a ideia de "fenômeno", construto que se refere a "tudo aquilo que intencionalmente está presente na consciência, sendo para esta uma significação" (Oliveira, 2009, p. 366). Para esses autores, toda a consciência é intencional, ou seja, é consciência de algo e não existe uma consciência que seja pura, isenta de valores, separada do mundo.

Na mesma lógica, não há objeto em si desvinculado da consciência que o percebe. O objeto é o fenômeno, o que aparece para a consciência. Essa filosofia traz a importante contribuição de que o mundo percebido é um mundo particular, com sentido único. A relação do sujeito com a droga é única. À Fenomenologia interessa esse ser do fenômeno, imbricado com este; importam as características singulares relacionais entre o ser e o fenômeno (Ribeiro, 2012, p. 67). Não se pode isolar laboratorialmente um fenômeno para poder compreendê-lo, pois se abdica assim, em detrimento de supostos universais, aquilo que é único.

As abordagens psicoterápicas de base existencialfenomenológica tiveram ampla influência de um filósofo chamado Martin Heidegger e de estudiosos de suas ideias, tais como Ludwig Binswanger e Medard Boss (Moreira, 2010). Para Heidegger, a psicologia de sua época estaria impregnada de uma visão limitada ao ente (plano ôntico) em detrimento do ser (plano ontológico) e isso determinaria, em última análise, uma dicotomia sujeito-objeto (Moreira, 2010, p. 727). Para esses autores, não há "ser” e "mundo" cindidos, pois o homem é um "ser-no- mundo" (Roehe, 2012, p. 17). Nesse sentido, a psicopatologia não poderia ser observada enquanto desvio de uma norma (padrão estatístico de uma determinada categoria de entes), mas como forma de expressão e significação de um ser.

Heidegger ainda deu contribuições para a pesquisa em psicologia alertando para a impossibilidade de obtenção de conhecimento "neutro", sendo a própria tentativa de neutralidade uma forma de envolver-se afetivamente. No campo da psicopatologia, é importante ressaltar ainda as contribuições de Karl Jaspers, psiquiatra alemão 
que introduziu o método fenomenológico nessa área de estudo. Esse autor fez em sua obra uma crítica à psicologia puramente "científica”, preocupada apenas com os sintomas objetivos (o que a tornava semelhante à fisiologia) em detrimento da observação da experiência subjetiva do sofrimento (Moreira, 2011, p. 174). É assim que nos filiamos a uma perspectiva ontológica de compreensão do sofrimento, segundo a qual se "compreende um sintoma ou síndrome não como uma coisa individual, mas como um estilo de ser no mundo, uma postura total, e que como tal pode ser encontrado em vários domínios da atividade humana” (Galli, 2009, p. 60).

Dentro de toda essa perspectiva de observação exposta, o ensaio foi o método de escrita que pareceu adequado. Além disso, foi uma forma de fugir de certo cientificismo que domina as práticas e discursos quando o assunto é a dependência química, que mostra a atualidade da crítica de Jaspers. Não se pretendeu encerrar algum assunto, compondo novas verdades absolutas, novas teorias a serem aceitas. Pelo contrário, pois no ensaio há "uma renúncia à segurança da teoria, à segurança da prática" (Larrosa, 2004, p. 39). Ele pressupõe pensar e repensar o pensado, já que tem como característica "uma incessante problematização e reproblematização de si mesmo" (Larossa, 2004, p. 32). "Pensar é ensaiar", escreveu Perls (Perls, 1966, p. 30). Esse gênero de escrita trabalha com uma ideia de experiência de momento, de aqui e agora, de processo, de construções que não são imutáveis. Sobre isso, afirma Larrosa:

no ensaio não se trata do presente como realidade, mas como experiência. No ensaio trata-se de dar forma a uma experiência do presente. É essa experiência do presente a que dá o que pensar, a que deve ser pensada. A questão do ensaio é o que nos acontece agora, quem somos agora, o que podemos pensar e o que podemos dizer e o que podemos experimentar agora, neste exato momento da história (Larrosa, 2004, p. 34).

Na tentativa de compor tais fechamentos, foi inevitável lançar mão de falas, de situações, de notícias, de produções culturais, enfim, de vivências que ajudaram a materializar o fenômeno estudado. Larrosa diz que "há que se buscar signos do presente, detalhes significativos, talvez miudezas, aspectos mínimos que pareçam banais, mas contemplados de outro modo, partindo de outro ponto de vista, de outra disposição, de modo que apareçam como vistos pela primeira vez” (2004, p. 35). Assim como o autor, entendo que trata-se de "procurar detalhes que possam funcionar como sintomas, também no sentido médico da palavra: sintomas de nossa saúde e de nossa doença, de nossa vida e de nossa rigidez, do que somos e já não podemos ou já não queremos ser" (p. 35).

\section{Problematizando a dependência sob enfoque da gestalt: figuras emergem}

\section{PESSOA: AQUELE SER QUE (ENTRE OUTRAS COISAS) DEPENDE DE DROGAS}

Era mais um dia chuvoso de agosto, desses de paisagem cinza, onde nada parece ser suficientemente gracioso ou memorável. O chuvisco, a névoa, o frio, a ausência de cores e sorrisos, eram o palco em que uma orquestra tocava sua canção urbana de ninar, metricamente regida pelo maestro-motor do ônibus. Gotas de chuva na janela do coletivo e meus quase cinco graus de miopia disfarçados com lentes descartáveis envelhecidas - que me irritavam os olhos! - tornavam tudo ainda mais entorpecedor. Coloco os fones de ouvido. Um cantor uruguaio com voz macia e violão suave cantava. "Deseo, mire donde mire te veo...". Sou interrompido bruscamente por alguém gritando para ser ouvido. Um homem, branco, 33 anos, goiano, com luzes no cabelo curto e crespo, oferecendo bugigangas para vender em prol de uma instituição que lhe tirara das drogas. "Dulce magnetismo, dos cargas opuestas buscando lo mismo", cantava o uruguaio. "A pessoa que depende de drogas...”, bradava o rapaz ("pessoa!” essa palavra ecoou em meus pensamentos) “... precisa da sua ajuda" ("que ajuda?” pensei eu). Os fones, afinal, não foram capazes de me ensurdecer. Eis que os sons tornaram-se, enfim, mais coloridos.

O episódio acima poderia passar despercebido e ser apenas um instante compondo um dia qualquer. Entretanto, há momentos que saltam à vista, figuram, tornando-se mais do que meras frações de tempo que se somam compondo horas. O mais interessante desse momento, aquilo que talvez o tenha dado destaque e trazido para o campo da experiência, do memorável, foi o poder de uma simples troca de palavras. Geralmente o termo que se ouve para a designação de alguém que tem um problema na sua relação com substâncias psicoativas é "dependente químico" ao invés do utilizado "pessoa que depende de drogas".

Essa simples mudança de palavras que poderia ser tomada como algo "óbvio", no entanto, abre uma discussão acerca do que, afinal, se diz quando alguém é "dependente químico”. Ou do que não se diz. Trata-se de ficar com o óbvio, conforme propunha Perls. Talvez a grande diferença nas duas formas de referir-se ao ser que desenvolveu uma dependência de uma ou várias substâncias psicoativas seja a inclusão do termo "pessoa". Tal inclusão é muito relevante, visto que, atualmente, está em discussão no país, no âmbito das políticas públicas sobre drogas, justamente esse “dependente”. Questiona-se: quem é ele? Seria um criminoso ou um doente?

Emmanuel Mounier (1905-1950), filósofo francês, dedicou-se a pensar sobre o seu conceito de "pessoa", tendo fundado, inclusive, um movimento chamado personalis- 
ta. Este autor, cujo pensamento se aproxima de filósofos existencialistas, como Heidegger e Gabriel Marcel, expõe tal conceito através da expressão "Permanência Aberta" (Rocha, 2011, p. 81). Com a ideia de "Permanência", Mounier considera a possibilidade de uma natureza ou essência humana; com a ideia de "Aberta", o autor ressalta a importância das escolhas como compositoras do homem, assim sendo, "se por um lado nenhuma essência pode esgotar o sentido da pessoa, por outro lado não estamos diante do puro fazer-se" (Rocha, 2011, p. 81). O autor ainda discorre sobre os termos "encarnação", “comunicação" e "vocação”, que seriam para ele estruturas que auxiliariam no entendimento do "mistério pessoal” (Mounier, 1076, p. 19, citado por Rocha, 2011, p. 81). Por "encarnação", Mounier acreditava, assim como entende a Gestalt-terapia, na unidade corpo-mente ou corpo-alma em oposição às dicotomias vigentes na época; por “comunicação”, o autor quer expressar a necessidade, no processo de personalização, da relação interpessoal em oposição ao individualismo; por "vocação", Mounier tenta expressar a característica que diferencia as pessoas em seu modo de escolher, engajar-se, agir (Rocha, 2011, p. 81).

A inclusão de uma "pessoa" no discurso inicia, para os fins deste ensaio, a construção de uma visão mais clara acerca do que está em questão quando nos propomos a refletir sobre a dependência química. Surge aí alguém, um "eu" compondo uma relação com um "isso" (Buber, 2003). O conceito de pessoa nos auxilia na construção da figura. Ora, não se trata apenas de uma doença, determinada por uma substância, por predisposições genéticas ou ambientais, totalmente externa às possibilidades de ação ("vocação") do ser, isentando-o de qualquer responsabilidade sobre si mesmo na relação. O uso de drogas pode ser entendido, inclusive, como uma forma de "comunicação", um modo de se pôr em comunidade, a comunidade dos usuários de drogas, as cracolândias e similares espalhadas pelo país, por exemplo.

Não podemos tratar a dependência química conferindo significados a partir de teorias pré-estabelecidas, com o compromisso de satisfazê-las, sem considerar a necessidade da suspensão do juízo (epoché) como passo para obtenção do conhecimento. Negar isso abalaria os fundamentos fenomenológicos da Gestalt-terapia. Como visto anteriormente, estamos falando de uma pessoa envolvida em um fenômeno, logo, é impossível dicotomizálos e abstraí-los a ponto de promover explicações fora da relação estabelecida. De maneira semelhante, se há uma "pessoa” em relação, não podemos promover uma psicoterapia de práticas universais e prescritivas como forma de abordagem da questão, pois, dessa forma, teríamos como consequência um processo de despersonalização e massificação do homem. Uma psicoterapia assim, no entanto, estaria de acordo com o processo de subjetivação o qual a lógica do capital e do consumo impõe atualmente. Sobre esse processo e o seu oposto, Laura Perls, décadas atrás, já fazia referências pertinentes e coerentes com a contemporaneidade:

Quando a conscientização e a expressão da singularidade e individualidade são reprimidas, temos uniformidade, tédio e uma cultura de massa fundamentalmente vazia de significação, em que a consciência da nossa própria morte torna-se tão insuportável que tem de ser alienada a qualquer preço, com "diversões", "gozando a vida" e outras futilidades acumuladas ou excitações artificiais (álcool, drogas, delinquência). Quando a singularidade e a individualidade são superinfatizadas, temos um falso "humanismo" com o homem como medida de todas as coisas, resultando em exageradas expectativas, frustração e desapontamento (Perls, 1961, p. 179).

É preciso, no entanto, ter um mínimo entendimento de alguns processos que podem estar envolvidos na dinâmica do uso de drogas para, assim, gestar uma forma de cuidado que promova a "pessoa". Nesse sentido, embora pouco estudada como tal dentro da Gestaltterapia, a dependência química tem sido vista como algo da ordem da neurose (Antunes, 2011; Parente, 2013; Sideroff, 1979).

O neurótico é uma pessoa em crise existencial: sente que suas necessidades não estão mais sendo atendidas pelo seu modo de agir, pois este se tornou obsoleto, porém, ao mesmo tempo, não consegue abandoná-lo (Perls, 1977a, p. 57). Essa condição torna-o "vago quanto ao presente porque o vê apenas através de óculos escuros, torturado em relação ao futuro porque o presente lhe escapa” (Perls, 1977a, p. 57). Essa pessoa tem como característica marcante a capacidade de manipulação, não de uma forma consciente, premeditada (configurando alguma conotação pejorativa ao termo), mas no sentido de agir sobre si mesmo e sobre o ambiente de forma a manter o status quo.

Poderíamos dizer que o neurótico é uma pessoa que tem "caráter" (Perls, 1977b, p. 21) o que corresponde a dizer que, diferentemente da forma como é utilizado no vocabulário cotidiano, é uma pessoa que possui uma figura cristalizada, um comportamento "petrificado, previsível” [que leva a uma perda da] "capacidade de lidar livremente com o mundo com todos os seus recursos" (Perls, 1977b, p. 21). Nesse sentido, a pessoa que se interrompe neuroticamente e que está, portanto, congelada em alguns comportamentos, está temporariamente incapaz de enfrentar sua crise existencial (Perls, 1977a, p. 60).

Segundo Parente (2013), a pessoa que dependente de drogas age como se apenas pela substância e pela sensação que esta causa existisse a possibilidade de ser-no-mundo. Isso pode, no entanto, ter uma resolução que ocorrerá "quando o paciente perceber que está manipulando seu meio de um modo que, não obstante quão com- 
plicado seja, é auto-defensivo e, quando tiver consciência das próprias técnicas manipulatórias, estará apto a fazer mudanças" (Perls, 1977, p. 60). Outro tema oriundo da fala daquele importante desconhecido, em uma linha de ônibus qualquer da cidade, que estimula a pensar sobre as questões que envolvem a dependência química e que tangencia as reflexões já realizadas, diz respeito à relação de ajuda que se estabelece entre o paciente e o terapeuta. Refletir sobre a condição neurótica não pode significar enclausurar o paciente em um diagnóstico, pois, não se trata de uma doença propriamente dita. Um posicionamento diante disso determina uma forma de se colocar em uma relação que possibilite, de fato, ajuda.

Carl Rogers, grande representante das vertentes humanistas da psicologia afirmou que "se, no meu encontro com ele [o paciente], o trato como uma criança imatura, como um aluno ignorante, como uma personalidade neurótica ou um psicopata, cada um desses conceitos limita o que ele poderia ser na nossa relação" (Rogers, 2001, p. 65). Rogers ressalta ainda a importância de se desenvolver uma relação de confiança e respeito, onde impere o desejo de compreensão em detrimento da prescrição de comportamentos e ainda uma renúncia a qualquer forma de impessoalidade, pois "as atitudes que consistem em recusar-se como pessoa e em tratar o outro como um objeto não têm grandes probabilidades de servir para alguma coisa" (Rogers, 2001, p. 55). A visão de homem das teorias que orientam essas reflexões nos conduz, assim como Rogers, a uma perspectiva de ser humano "em construção", ou seja, em vias de "tornar-se quem é" (p. 65). $\mathrm{O}$ movimento inerente à pessoa de impulsão ao crescimento pessoal tornou-se um conceito fundamental na obra de Rogers, chamado por ele de "Tendência Atualizante" (Moreira, 2009, p. 8).

Abraham Maslow, outro autor da vertente humanista da psicologia, expressa opinião semelhante, quando fala de uma "Natureza Interna Essencial" que deve ser expressa e encorajada em uma relação de ajuda como condição para um desenvolvimento sadio (Maslow, 1968, p. 27). Nesse sentido, o uso de substâncias insere-se com alguma importância e significação no processo de crescimento do sujeito e cabe ao terapeuta, independente de juízos, constituir uma relação que permita a emergência de novas normas e liberação de potencialidades.

\section{A PRODUÇÃO DE DEPENDÊNCIA E A DESSENSI- BILIZAÇÃO CONTEMPORÂNEA}

É mais um dia de trabalho numa central telefônica de telessaúde dedicada a fazer um acompanhamento a usuários de drogas. Atendo o telefone. Saudamo-nos. Automaticamente, crio uma imagem mental da pessoa que está falando, afinal, como seria possível atender só uma voz, uma parte de ser humano? Humanos têm pele, ossos, cor... É um usuário de crack, mas tem voz de... de que mesmo? De gente "normal" é o julgamento que emerge. Minha voz é "normal" como a dele? Terão feito algum estudo sobre a voz de um usuário de crack? A julgar pela voz, poderia estar no meu lugar. Seria um trote? Surge a demanda: - "Eu queria que o senhor me desse uma orientação sobre o que eu faço pra parar de usar crack". A responsabilidade de uma vida recai sobre mim. Conscientizo-me de um desconforto nas costas (pela posição na cadeira? pelo tamanho do encargo?). Talvez eu já estivesse arqueado há vários minutos. Movimento-me. Falamos muito. Sinto sede. A água de minha garrafa está quente, assim como a sala. Após alguns minutos de conversa e de construção de uma extensa balança decisional, pergunto: - "Como você se sente olhando essa balança?". Segue uma fração de instante, preenchida apenas por um murmúrio de dúvida prolongado. Objetos sobre a mesa testemunham a ansiedade do terapeuta que coça a cabeça. O paciente responde: - "Nada".

O usuário de drogas é visto, de maneira geral, como uma pessoa destituída de seu "poder" pessoal. Ele precisa de uma força externa que o "tire" das drogas, como um remédio miraculoso, uma orientação sobre o que fazer, uma pessoa, entre outros subterfúgios. Em outras palavras, necessita de suporte ambiental, porquanto não o encontra em si mesmo. Em se tratando de dependência química, o desenvolvimento do autossuporte por parte do paciente é de capital importância para qualquer mudança pretendida (Sideroff, 1979; Parente, 2013). Perls afirma que, para ultrapassar a necessidade de apoio ambiental, é preciso redirecionar de forma criativa as energias que estão sendo investidas no bloqueio neurótico (1977a, p. 71). O terapeuta, por sua vez, tem papel fundamental nesse processo:

Se o terapeuta dá ao paciente apoio ambiental - em outras palavras, apoia sua necessidade transferencial - está sendo apenas um joguete nas mãos da neurose do paciente. Mas se, por outro lado, torna possível ao paciente assimilar o bloqueio e o material bloqueado, identificando-se com ele e diferenciando-o dele, facilita o desenvolvimento do paciente (Perls, 1977a, p. 71).

O terapeuta que assume a responsabilidade sobre o paciente de forma a gerar disparidade hierárquica, que se coloca na posição de detentor de saberes ocultos sobre o paciente, ou no lugar de quem prescreve condutas adequadas está, nessa visão, contribuindo para que o paciente permaneça em uma posição dependente. Poderíamos chamar de "terapeuta codependente", pois estaria, nesse sentido, produzindo mais dependência: não mais da

\footnotetext{
Diz-se codependente o indivíduo, geralmente familiar, que "quer controlar o comportamento do dependente e que assume um papel de cuidador/controlador do outro" (Parente, 2013, p. 18). O codependente tende a orientar sua vida apenas para o controle do dependente, abafando a liberdade do outro e a sua, pois se esquece de si mesmo.
} 
droga, mas de si. Sobre isso, Galli afirma que "somos profissionalmente tomados pela compulsão do 'orientar', do 'resolver', do 'salvar', do 'curar' e como isso tiramos a oportunidade da pessoa encontrar seu próprio caminho" (2009, p. 11).

O ponto de partida para o desenvolvimento do autossuporte não pode ser outro senão o próprio indivíduo em seu estado atual (Beisser, 1975). A mudança ocorre quando o paciente se torna uma ancoragem para si mesmo e quando "abandona, pelo menos de momento, aquilo em que gostaria de se tornar e tenta ser aquilo que é" (Beisser, 1975, p. 111). Fomentar essa postura é função do terapeuta que trabalha com dependentes químicos. As estratégias de redução de danos podem contribuir para um acolhimento diferente de um jeito de ser que causa sofrimento sem, no entanto, perder-se em um ideal de abstinência total, por vezes, ainda distante.

O pensamento de Georges Canguilhem, que contribuiu para a formação do campo da saúde coletiva, parece se aproximar muito nesse ponto. Para o autor, normal e patológico não são determinações estatísticas produzidas pela ciência, mas dizem respeito ao sofrimento subjetivo do paciente (ele que se percebe doente) e sua incapacidade de criar novas normas de vida que permitam seu crescimento (Ramminger, 2008). O próprio Canguilhem afirma: "O doente sente sua potência diminuída em relação a si mesmo, e é isto que deveria ser o ponto de ancoragem das práticas de saúde" (Canguilhem, 2006, citado por Ramminger, 2008, p. 90). A saúde estaria ligada ao (re)empoderamento do indivíduo. Esse conceito (neologismo advindo do inglês "empowerment") envolve tanto a sensação de poder pessoal (empowerment psicológico) quanto a possibilidade efetiva de agir sobre sua própria realidade (empowerment comunitário) a fim de transformá-la (Carvalho, 2004, p. 1092). Conforme afirma Carvalho, é preciso "trabalhar com uma noção de parceria entre profissionais, indivíduos e comunidades no lugar da relação hierárquica que confunde o trabalhador com o provedor de serviços e o usuário com o cliente" (p. 1094).

Canguilhem afirma ainda que a doença não pode ser vista apenas como algo negativo, pois ela é, em certo sentido, "inovadora", criativa (Canguilhem, 2006 citado por Ramminger, 2008). A Gestalt-terapia, por sua vez, também enxerga a doença de maneira semelhante. Entende-a como fruto de um ajustamento criativo, que, devido a cristalização, tornou-se ajustamento neurótico. Nesse sentido, a aproximação da Gestalt-terapia, representante da perspectiva fenomenológico-existencial atual escolhida para debater a dependência química neste ensaio, com o campo da saúde coletiva é bastante potente por não ser uma aproximação apenas temática, permitindo entendimentos, olhares e trocas semelhantes e importantes.

Desenvolver o autossuporte e devolver a capacidade normativa, contudo, não são tarefas fáceis, já que o dependente costuma mostrar-se, como o excerto acima pode exemplificar, com pouca capacidade de contato consigo próprio e com os outros (Sideroff, 1979, p. 355), podendo estar emperrado em diversos mecanismos de evitação do contato já conhecidos na literatura gestáltica, por exemplo, a Introjeção, a Projeção, a Confluência, a Retroflexão, a Deflexão e o Egotismo. Pela Introjeção o dependente pode estar cercado de "deverias" que são manifestados, por exemplo, na forma de expectativas sobre como precisa agir e ser e de juízos de valor sobre sua vida e comportamento; a Introjeção gera "uma luta até o empate [...] onde a personalidade fica imobilizada para qualquer crescimento e desenvolvimento posteriores" (Perls, 1977a, p. 48). Na Projeção o paciente drogadito pode se interromper expropriando partes de si de onde provêm seus impulsos e culpabilizando terceiros por esses seus conteúdos (Perls, 1977a, p. 50).

Por meio da Confluência pode se instaurar uma "confusão" (Perls, 1977a, p. 109), impedindo que o paciente perceba quais são os anseios e fazendo com que viva uma vida vazia, que não é autenticamente sua, em que o próprio desejo de abstinência pode não lhe pertencer. Na Retroflexão o dependente pode estar dirigindo sua agressividade contra si próprio, via utilização de drogas, de forma autodestrutiva (Parente, 2013, p. 22).

Pela Deflexão o paciente pode evitar comunicar-se com sua dor e expressá-la, buscando alívio em substâncias psicoativas (Parente, 2013, p. 22). No Egotismo, o uso da droga pode ser entendido como uma tentativa de contato consigo mesmo que se solidifica e perdura, impedindo a fluência da dinâmica saudável de contato e fuga (Parente, 2013, p. 22).

Todos esses exemplos de interrupções, no entanto, são apenas suposições, na medida em que não é possível compreender aprioristicamente o que se passa com o dependente químico e sua relação com a droga. A GestaltTerapia é uma psicoterapia dialógica, conforme veremos adiante, preocupada com a "exploração do entre" (Hycner \& Jacobs, 1995, p. 29), de onde emergem as significações singulares.

Cabe ainda discorrer um pouco sobre a espantosa constatação do paciente que (não) sente "nada". Tal afirmação é comum na clínica e não somente a de dependentes químicos. É uma realidade contemporânea que já se delineava há três décadas, conforme afirmou Perls:

Se a emoção é, como supus, a força básica que dá energia a toda ação, ela existe em todas as situações da vida. Um dos problemas mais sérios do homem moderno é que ele se dessensibilizou a si mesmo para tudo, menos para o tipo mais catastrófico de resposta emocional. A ponto de não ser capaz de perceber-se sensivelmente, a ponto de se tornar incapaz da liberdade de escolha que resulta numa atitude coerente (Perls, 1977a, p. 96). 
Para Perls, a capacidade de escolha e de mudança está intimamente ligada à possibilidade de percepção de si e do que está envolvido em uma dada situação. Essa percepção de si não corresponde a uma resolução da ambivalência ${ }^{2}$, por exemplo, pois ela existe em qualquer situação, visto que não podemos petrificar nossas emoções sobre as coisas (Perls, 1977a, p. 63). Essa percepção é uma autoconsciência no aqui-e-agora e é um caro conceito da Gestalt-terapia: a awareness. Importante ressaltar, todavia, que ela não é um objetivo em si mesmo da terapia, mas é um meio que permite ao ser um melhor contato com o mundo e consigo (Hycner \& Jacobs, 1995, p. 30). Esse contato "perdido" pelo homem contemporâneo em sua ânsia por conseguir algo que nunca chega, mas que reduz a experiência de tudo que já se tem, é a experiência que a Gestalt-terapia almeja fornecer.

\section{A SINGULARIDADE DA EXPERIÊNCIA}

Diz um pai, cliente de um serviço de telessaúde, sobre seu filho usuário de substâncias psicoativas: - "Ele usa, mais ou menos, uma carteira e meia por dia, fora palheiro e cachimbo, que usa só em casa... se ele sair com o palheiro na rua vão abordar ele, achando que é outra coisa". Ele continua: - "E bebe! Toma mais ou menos uma garrafa e meia de cachaça por dia! Isso durante a semana, no final de semana toma o que tiver...”. Ele ainda acrescenta: - "o psiquiatra do CAPS disse para ele experimentar Maconha, porque assim vai ajudar ele a reduzir as outras coisas que ele usa... ele ainda tá pensando nisso... será que funciona?” Após um tempo de conversa, conclui o cliente: - "A droga é como a 'grande amada' para ele".

A bela metáfora que um pai capta diante do sofrimento de seu filho parece uma interessante introdução a um tema central na Gestalt-terapia que é a sua postura dialógica, meio que proporciona a compreensão de um indivíduo em sua singularidade e, mais importante que isso, permite que este desenvolva seu autoconhecimento. Dialógico é, pois, a forma primordial de ser e de se colocar em relação que permitirá a emergência da alteridade do outro. E é só nesse contexto que o conceito de autossuporte se sustenta, caso contrário, seria mera ratificação de uma visão individualista de homem; a singularidade só surge de uma relação com o outro que confirme a experiência (Hycner \& Jacobs, 1995, p. 31).

Embora a Gestalt-terapia possua técnicas estas não podem ser prescritas, tal como receitas, para se lidar com determinados pacientes com determinadas patologias. As técnicas só têm sentido no "entre" e é nele que podem produzir ampliação do fluxo da awareness e me-

\footnotetext{
2 Ambivalência é o nome dado às "motivações flutuantes e conflitantes” (Bordin, Figlie, Laranjeira, 2004, p. 224) que os dependentes químicos apresentam que os deixa divididos entre querer e não querer largar determinada substância. Uma técnica comumente usada para lidar com a ambivalência é a Balança Decisional.
}

lhores possibilidades de contato consigo e com o meio. A grande questão que se coloca é como produzir tal contato dialógico, de forma que o dependente químico possa ter os benefícios terapêuticos que procura. Richard Hycner e Lynne Jacobs (1995), atravessados pela perspectiva ontológica Buberiana, citam alguns pontos a serem observados, os quais creio serem importantes no atendimento de pacientes que sofrem com a dependência. Os autores falam da necessidade de se "rastrear", ou seja, ficar com a experiência fenomenológica no aqui-e-agora e em atitude confirmadora, ou seja, sem exigências (da abstinência, por exemplo) ou juízos críticos (acerca de recaídas, lapsos). Além disso, seria importante voltar-se o máximo possível para o outro no intuito de estar plenamente presente, colocando "entre parênteses" a teoria, os (pre) conceitos, os anseios, entre outros, o que não significa uma neutralidade, mas uma consciência da existência de tais conteúdos e uma tentativa de colocá-los como fundo da experiência para poder "ver o outro em sua 'alteridade' - que é diferente de mim, e de qualquer necessidade minha” (Hycner \& Jacobs, 1995, p 39).

É importante ressaltar ainda a ideia de Hycner e Jacobs acerca da diferença entre a postura dialógica ou "atitude Eu-Tu”, e o "momento Eu-Tu” (Hycner \& Jacobs, 1995, p. 34). A atitude Eu-Tu é a abertura necessária - cujas pistas foram anteriormente debatidas - para que o momento Eu-Tu, o encontro transformador, possa acontecer. Para ocorrência do encontro, no entanto, é preciso haver uma dinâmica de aproximação e afastamento, ou seja, é necessária uma alternância de atitude Eu-Tu - dirigida ao outro - e atitude Eu-Isso - dirigida a um propósito, um objetivo - sendo essa alternância um requisito de saúde. Essa última não é má em si mesma, uma fixação nela é que produz a "coisificação" do outro (p. 34). O diálogo, por sua vez, é diferente da dialética que pode ocorrer na psicoterapia, quando terapeuta e paciente se confrontam (por exemplo, o terapeuta trabalhando sob a lógica da abstinência total, enquanto o paciente não vê seu uso de cigarro como problema), ou ainda, quando o próprio paciente divide-se em um confronto interno. Esse confronto interno, Perls denominou Top Dog/Under Dog e pode se manifestar, por exemplo, em uma parte dominadora do usuário que quer deixar o Álcool e uma dominada que se põe em posição de impotência perante a droga.

\section{VIDAS INFAMES: À GUISA DE FECHAMENTO}

Manhãs ensolaradas e de clima ameno! Como são prazerosas! Elas têm um cheiro de relva que fica quando o orvalho começa a evaporar. Os raios solares tocam a pele e vão acordando-nos, dando sentido ao esforço do despertar contra a vontade. Era uma manhã dessas, tão escassas no último inverno que os pássaros já cantavam e revoavam clamando pela primavera. Na parada de ônibus, velha testemunha de tantos sonhos e atrasos, aguardo. Em meio à beleza do dia, algo destoa. No outro lado da rua, passa um 
homem. Invisível. Ninguém mais parece vê-lo e, por um momento, penso ser uma alucinação. Será ele "real"? Percebo, então, que é uma dessas figuras "famosas" do bairro, de quem se sabe "tudo", embora nunca se tenha ouvido falar "nada": usam drogas e vivem na rua. O homem vestia-se de trapos e carregava em volta de si um velho cobertor surrado, dando-lhe um ar médio-oriental. Dormiu numa praça, acordou-se cedo e agora andava cambaleante com uma garrafa - de embalagem conhecida - a tiracolo, conversando com $o$ vento. Este parecia informar-lhe sobre as lixeiras mais fartas. O ônibus passa, vidas seguem, cada qual buscando o que lhe falta.

Foucault (1977) chamou de "infames" as vidas dos homens que parecem não ter existido - e, no caso do homem do excerto, parece não existir mesmo que em vida. Vidas que só se destacam se capturadas pelo discurso jornalístico, pelo boletim policial, pelo prontuário médico, caso contrário, passam incógnitas. Fazem parte das paisagens urbanas e "não mais existem senão através das poucas palavras terríveis [...] destinadas a torna-los indignos para sempre da memória dos homens" (Foucault, 1977, p. 208). O contato com o poder - neste caso um poder que produz um saber - permite que se evidenciem, que figurem. Possivelmente tal pessoa teria muito mais a dizer sobre si do que este estudo pode encerrar, porém, o acaso, o tempo, a vida, não permitem, infelizmente, mais do que algumas reflexões.

"Os infames" têm, na maior parte de seu tempo de vida, existência apenas estatística e importância relativa ao quanto atrapalham a vida alheia: a segurança, a estética, a higiene, a saúde. Se por vezes são alvo de políticas públicas, é preciso lembrar o quanto estas estão, muitas vezes, impregnadas de uma necessidade de higienização e controle das condutas. Ramminger afirma que desde o momento em que o Estado passou a se preocupar com a vida dos indivíduos "o acento esteve mais na normalização de condutas e estilos de vida, com a culpabilização do indivíduo, do que na transformação dessas limitações sociais de vida” (2008, p. 84). A perspectiva da saúde coletiva, nesse sentido, é a ampliação possível e desejável da saúde pública (política pública, em certo sentido, policialesca e higienista), pois visa romper com os discursos biológicos que agenciam tal normalização, buscando uma posição transdisciplinar, com a inclusão da perspectiva política, ética e simbólica na discussão sobre a saúde da população (Ramminger, 2008, p. 75).

As pessoas que dependem de drogas hoje atualizam as ideias de Foucault expressas anteriormente, na medida em que são vistas todos os dias, mas apenas nos noticiários policiais, como autores de delitos motivados pela droga e se "não são tratados como marginais ou criminosos, aparecem outros discursos sobre o uso das substâncias ou mesmo sobre as histórias de vida dos sujeitos" (Silva, 2010, p. 183). As falas correntes são carregadas da mesma lógica que deu origem aos sanatórios, que é a do confinamento, numa luta anacrônica e desesperada para se lidar com tamanho problema social. Como produto dessa visão, nem o dependente desenvolve autossuporte, nem o meio desenvolve uma relação de ajuda potente.

O estigma da dependência é de tal modo poderoso que obnubila qualquer outra percepção acerca do indivíduo. Hycner e Jacobs, sobre isso, afirmam:

Atualmente, com muita frequência, identificamos a pessoa com alguma motivação psicológica que se sobressai, como se esta fosse a única dimensão de sua existência. Talvez, também, com demasiada frequência, deixemos de nos perguntar que contexto é esse da existência da pessoa que faz com que um motivo ou comportamento seja figura em determinado momento (Hycner \& Jacobs, 1995, p. 36).

Somado ao estigma, vemos ainda que as soluções propostas para a questão da dependência química aparentam ser impelidas sempre por uma urgência - que parece ser atravessada pelo mesmo imediatismo do prazer do entorpecente - e os profissionais de saúde, via de regra, são comumente convocados a trabalhar "por atacado".

As consequências do cuidado dispensado atualmente ao dependente químico parecem apontar para uma abismal redução do ser, manifesta na "desqualificação de seus talentos" e no "impedimento da atualização de suas potências de vida” (Silva, 2010, p. 185). O modo atual de enxergar o dependente vai totalmente de encontro ao que propõe a Gestalt-terapia e inclusive a sua visão de homem, na medida em que o sintoma não constitui o todo do indivíduo, mas é uma dimensão que figura em determinado momento e tem seu significado, relacionado a esse todo.

Da mesma forma, o homem pode ser visto como parte do mundo e em relação com ele. Seus sintomas se relacionam com esse todo maior que sua existência e nessa relação se produzem. O dependente não é, pois, o único "doente”, o único “culpado”, mas é parte significativa e atualizadora de um todo cuja capacidade normativa cristalizou. Julgamentos estigmatizantes, muitas vezes, servem apenas "para ocultar uma realidade sociocultural econômica que 'vem transformando o planeta num mercado e, seus habitantes em zumbis hiperativos incluídos ou trapos humanos excluídos"” (Rolnik, 2007, p. 18, citado por Silva 2010, p. 185).

Não basta, nesse sentido, pensar apenas em intervenções de núcleo que possam ser utilizadas pelo psicólogo em seu consultório particular, como se o dependente fosse "o problema” e o terapeuta a solução. É preciso pensar no campo olhando todas as partes que estão em relação e constituem o modo de ser contemporâneo, pois, a desconexão dessas partes elimina totalmente o significado do fenômeno (Perls, 1977a, p. 193). Galli contribui com 
essa ideia, afirmando que "no lugar de classificar o paciente dentro de um quadro de doenças psíquicas, é preciso analisar as forças que estão atuando para produzir esse sofrimento" (2009, p. 9). Trata-se de construir um olhar e um cuidado menos individualizantes, que fujam do mero controle dos corpos e das saídas simplificadoras e manipuladoras a vida (Galli, 2009, p. 11). Essa talvez seja a grande contribuição da Gestalt-terapia e suas bases filosóficas.

\section{Referências}

Antunes, L. (2011). O uso de drogas sob o enfoque da GestaltTerapia. Aware, 2(1), 30-36.

Aranha, M. L. de A., \& Martins, M. H. P. (1993). Filosofando: Introdução à Filosofia (2. ed.). São Paulo: Moderna.

Bordin, S., Figlie, N. B., \& Laranjeira, R. (2004). Aconselhamento em Dependência Química. São Paulo: Roca.

Beisser, A. R. (1975). Teoria Paradoxal da Mudança. Em J. Fagan, \& I. L. Shepherd (Orgs.), Gestalt-Terapia: Teoria, Técnicas e Aplicações (2. ed.) (p. 110-114). Rio de Janeiro: Zahar.

Buber, M. (2003). Eu e Tu (6. ed.). São Paulo: Centauro.

Carlini, C. M. A., Galduróz, J. C. F., Noto, A. R., Nappo, S. A., \& Fonseca, A. M. (2003). Levantamento Nacional Sobre o Uso de Drogas Entre Crianças e Adolescentes em Situação de Rua nas 27 Capitais Brasileiras. São Paulo: Centro Brasileiro de Informações Sobre Drogas Psicotrópicas.

Carlini, E. A., Galduróz, J. C. F., Noto, A. R., Fonseca, A. M., Carlini, C. M. A., Oliveira, L. G. de, Nappo, S. A., Moura, Y. G. de, \& Sanchez, Z. V. D. M. (2005). II Levantamento Domiciliar Sobre o Uso de Drogas Psicotrópicas no Brasil: Estudo Envolvendo as 108 Maiores Cidades do País. São Paulo: Centro Brasileiro de Informações Sobre Drogas Psicotrópicas.

Carvalho, S. R. (2004, julho/agosto). Os Múltiplos Sentidos da Categoria "Empowerment” no Projeto de Promoção à Saúde. Cadernos de Saúde Pública, 20(4), 1088-1095. Recuperado em 28 de outubro, 2013, de http://www.scielo.br/pdf/csp/ v20n4/24.pdf.

Conselho Regional de Psicologia de São Paulo. (2012). Álcool e Outras Drogas. São Paulo: Autor. Disponível em: http:// www.crpsp.org.br/portal/comunicacao/livro-alcool-drogas/ crpsp-alcool-e-outras-drogas.pdf.

Fiocruz. (2013). Estimativa do Número de Usuários de Crack e/ou Similares nas Capitais do País: Livreto Domiciliar. [S. 1.]: Autor.

Foucault, M. (1977). A vida dos homens infames. Em M. Foucault, Estratégia, poder-saber (Ditos e escritos IV). Rio de Janeiro: Forense Universitária.

Galli, L. M. P. (2009). Um olhar fenomenológico sobre a questão da saúde e da doença: a cura do ponto de vista da Gestaltterapia. Estudos e Pesquisas em Psicologia, 9(1), 58-10.
Goldman, C., Castro, A. L. S., Silveira, A. R., Batisti, M., Gorgulho, M., Gonçalves, M. G., \& Guerra, J. (Orgs.) (2010). Subjetividade do Consumo de Álcool e Outras Drogas e as Políticas Públicas Brasileiras. Brasília: Conselho Federal de Psicologia.

Hycner, R., \& Jacobs, L. (1995). Relação e Cura em GestaltTerapia. São Paulo: Summus.

Larrosa, J. (2004, janeiro/junho). A operação ensaio: sobre o ensaiar e o ensaiar-se no pensamento, na escrita e na vida. Educação e Realidade, 29(1), 27-43.

Maslow, A. H. (1968). Introdução à Psicologia do Ser. Rio de Janeiro: Eldorado.

Moreira, V. (2009, janeiro/junho). A Gestalt-Terapia e abordagem Centrada na Pessoa são Enfoques Fenomenológicos? Revista da Abordagem Gestáltica, 15(1), 3-12. Recuperado em 31 de outubro, 2013, de Pepsic (Periódicos Eletrônicos em Psicologia): pepsic.bvsalud.org.

Moreira, V. (2011, julho/dezembro). A contribuição de Jaspers, Binswanger, Boss e Tatossian para a psicopatologia fenomenológica. Revista da Abordagem Gestáltica, 17(2), 172-184. Recuperado em 25 de outubro, 2013, de Pepsic (Periódicos Eletrônicos em Psicologia): pepsic.bvsalud.org

Parente, N. M. A. (2013, janeiro/dezembro). Dependência e codependência do álcool: uma leitura gestáltica sobre saúde e doença. Revista de Gestalt, 18(18), 17-28.

Passos, E. (2010). Pensar Diferentemente o Tema das Drogas e o Campo da Saúde Mental. Em L. M. B. Santos (Org.), Outras Palavras Sobre o Cuidado de Pessoas Que Usam Drogas (p. 7-14). Porto Alegre: Ideograf.

Oliveira, S. R. M. (2009). Fenomenológico-existencial/ Compreensiva. Em S. D. Seibel, (Org.), Dependência de Drogas. São Paulo: Atheneu.

Perls, L. (1961). Abordagem de um Gestalt-Terapeuta. Em J. Fagan, \& I. L. Shepherd (Orgs.), Gestalt-Terapia: Teoria, Técnicas e Aplicações (2. ed.) (p. 174-180). Rio de Janeiro: Zahar.

Perls. F. S. (1966). Quatro Palestras. Em Fagan, J., Shepherd, I. L. (Orgs.), Gestalt-Terapia: Teoria, Técnicas e Aplicações (2. ed.) (p. 27-60). Rio de Janeiro: Zahar.

Perls, F. S. (1977a). A Abordagem Gestáltica e Testemunha Ocular da Terapia. Rio de Janeiro: Zahar.

Perls, F. S. (1977b). Gestalt-terapia Explicada (3. ed.). São Paulo: Summus.

Ramminger, T. (2008). Entre a normatividade e a normalidade: contribuições de G. Canguilhem e M. Foucault para as práticas de saúde. Mnemosine, 4(2), 68-97.

Ribeiro, J. P. (2011). O conceito de mundo e de pessoa em gestaltterapia. São Paulo: Summus.

Ribeiro, J. P. (2012). Gestalt-terapia: refazendo um caminho (8. ed.). São Paulo: Summus. 
Rocha, A. G. V. (2011). A antropologia personalista de Emmanuel Mounier e os Direitos Humanos. Pesquisa em Foco: Educação e Filosofia, 4(4), 77-90.

Roehe, M. V. (2012, janeiro/março). A Psicologia Heideggeriana. Psico, 43(1), 14-21.

Rogers, C. (2001). Tornar-se Pessoa (5. ed.). São Paulo: Martins Fontes.

Sideroff, S. I. (1979). Use of Gestalt Therapy Within a Drug Treatment Program. Baywood Publishing Company, 9(4), 349-357.

Silva, F. C. (2010). Redução de Danos: campo de possibilidades para práticas não proibicionistas em saúde. Em L. M. B. Santos (Org.). Outras Palavras Sobre o Cuidado de Pessoas Que Usam Drogas (p. 177-188). Porto Alegre: Ideograf.

World Health Organization. (2012). World Drug Report. Nova York: Author.

Yontef, G. M. (1998). Processo, Diálogo e Awareness: Ensaios Sobre Gestalt-terapia (2. ed.). São Paulo: Summus.

Luiz Gustavo Santos Tessaro - Psicólogo pelo Centro Universitário Metodista IPA, especializando em Gestalt-terapia pela Comunidade Gestáltica de Florianópolis.

E-mail: tessaro.luiz@gmail.com

Cleber Gibbon Ratto - Pesquisador e bolsista de Produtividade CNPq. Psicólogo. Psicoterapeuta. Doutor em Educação. Docente do PPGEDU/ UNILASALLE. Docente do Centro Universitário Metodista IPA.

Recebido em 16.02.2014 Primeira Decisão Editorial em 09.07.2014 Aceito em 12.01.2014 